\title{
Development of Polyimide Foam for Aircraft Sidewall Applications
}

\author{
Richard J. Silcox ${ }^{1}$, Roberto J. Cano ${ }^{2}$ and Brian Howerton ${ }^{3}$ \\ NASA Langley Research Center, Hampton VA 23681-2199, USA \\ J. Stuart Bolton ${ }^{4}$ and Nicholas N. Kim ${ }^{5}$ \\ Purdue University, West Lafayette, IN 47907-2031, USA
}

\begin{abstract}
In this paper, the use of polyimide foam as a lining in double panel applications is considered. It is being investigated here as a replacement for aircraft grade glass fiber and has a number of attractive functional attributes, not the least of which is its high fire resistance. The test configuration studied here consisted of two $1 \mathrm{~mm}(0.04$ in.) thick, flat aluminum panels separated by $12.7 \mathrm{~cm}(5.0$ in.) with a $7.6 \mathrm{~cm}(3.0 \mathrm{in}$.$) thick layer of foam$ centered in that space. Random incidence transmission loss measurements were conducted on this buildup, and conventional poro-elastic models were used to predict the performance of the lining material. Results from two densities of foam are considered. The Biot parameters of the foam were determined by a combination of direct measurement (for density, flow resistivity and Young's modulus) and inverse characterization procedures (for porosity, tortuosity, viscous and thermal characteristic length, Poisson's ratio and loss factor). The inverse characterization procedure involved matching normal incidence standing wave tube measurements of absorption coefficient and transmission loss of the isolated foam with finite element predictions. When the foam parameters determined in this way were used to predict the performance of the complete double panel system, reasonable agreement was obtained between the measured transmission loss and predictions made using a commercial statistical energy analysis code.
\end{abstract}

\section{Introduction}

I $\mathrm{n}$ this paper, the use of polyimide foam as a lining in double panel applications is considered. The material used in the present work is a polyimide foam developed jointly between PolyuMAC TechnoCore, Inc. and the NASA Langley Research Center (LaRC) Advanced Materials and Processing Branch. Polyimide foam has a number of attractive functional attributes, not the least of which is its high fire resistance, making its use desirable in some sound transmission applications, including aircraft sidewall treatments. However, initial testing found that the flow resistivity of the foam was too high to provide optimal acoustic dissipation. As a result, a process was developed to reduce the foam's flow resistivity by mechanically compressing it in a systematic manner. All results presented here are for polyimide foams that have been treated with this process. The particular configuration studied here consisted of two $1 \mathrm{~mm}(0.04 \mathrm{in}$.) thick, flat aluminum panels separated by $12.7 \mathrm{~cm}(5.0 \mathrm{in}$.), with a $7.6 \mathrm{~cm}(3.0 \mathrm{in}$.) thick layer of foam centered in that space. Random incidence transmission loss measurements were conducted on this buildup, and conventional poro-elastic models were used to predict the performance of the lining material. The Biot parameters of the foam were determined by a combination of direct measurement (for density, flow resistivity and Young's modulus) and inverse characterization procedures (for porosity, tortuosity, viscous and thermal characteristic length, Poisson's ratio and loss factor). The inverse characterization procedure involved matching normal incidence standing wave tube measurements of absorption coefficient and transmission loss of the isolated foam with finite element predictions. When the foam parameters determined in this way were used to predict the performance of the complete double panel system, reasonable agreement was obtained between the measured

\footnotetext{
${ }^{1}$ Chief Engineer for Acoustics, Research Directorate, Mail Stop 463, Associate Fellow AIAA.

${ }^{2}$ Research Engineer, Advanced Materials and Processing Branch, Mail Stop 226.

${ }^{3}$ Research Engineer, Structural Acoustics Branch, Mail Stop 463, Senior Member AIAA.

${ }^{4}$ Professor, Ray W. Herrick Laboratories, School of Mechanical Engineering.

${ }^{5}$ Graduate Research Assistant, Ray W. Herrick Laboratories, School of Mechanical Engineering.
}

1

American Institute of Aeronautics and Astronautics 
transmission loss and predictions made using a commercial statistical energy analysis code. Note that previously published work related to polyimide foams has concentrated on its anisotropy ${ }^{1}$ and the effect of rear surface mounting conditions in standing wave tubes. ${ }^{2}$

PolyuMAC polyimide foam insulation is the result of a joint development between PolyuMAC TechnoCore, Inc. and NASA LaRC, and is being commercialized by PolyuMAC under a joint ownership agreement. A previously developed NASA LaRC foam, given the designation TEEK, is a higher density, structural foam that is relatively expensive to produce. A need was identified by both LaRC and PolyuMAC TechnoCore, Inc. for a lower cost, lowdensity, flexible polyimide foam, which was designed to have excellent thermal and acoustical insulation properties for naval shipboard applications. This newly co-developed polyimide foam insulation ${ }^{3,4}$ had the physical property characteristics to meet the requirements of the applications of interest, including aircraft sidewall insulation. These new polyimide foams are produced at low densities ranging from 3.2 to $16 \mathrm{~kg} / \mathrm{m}^{3}(0.2$ to 1.0 pounds per cubic foot (pcf)) and can be utilized as thermal and/or acoustical insulation. It is important to note that polyimide materials are inherently fire retardant due to their chemical composition. Further, it was found these foams could be treated with NyeBar ${ }^{\circledR}$ from Nye Lubricants, Inc. to make the material hydrophobic with negligible effect on its weight or acoustic properties. This new foam technology has the advantage over previous polyimide foams of being manufactured and cured using microwave energy resulting in lower cost and faster production rates. Figure 1 shows the general workflow by which the polyimide foam is manufactured. This technology allows production of both rigid and flexible foam insulation while the previous technology (TEEK) could only be used to produce rigid, structural foam. This technology represents the first polyimide foams that rise at room temperature and are then cured using a microwave, thus producing foam insulation with acceptable thermal and acoustic insulating properties.

(b)Initial air cure

(d)Hi-temp oven

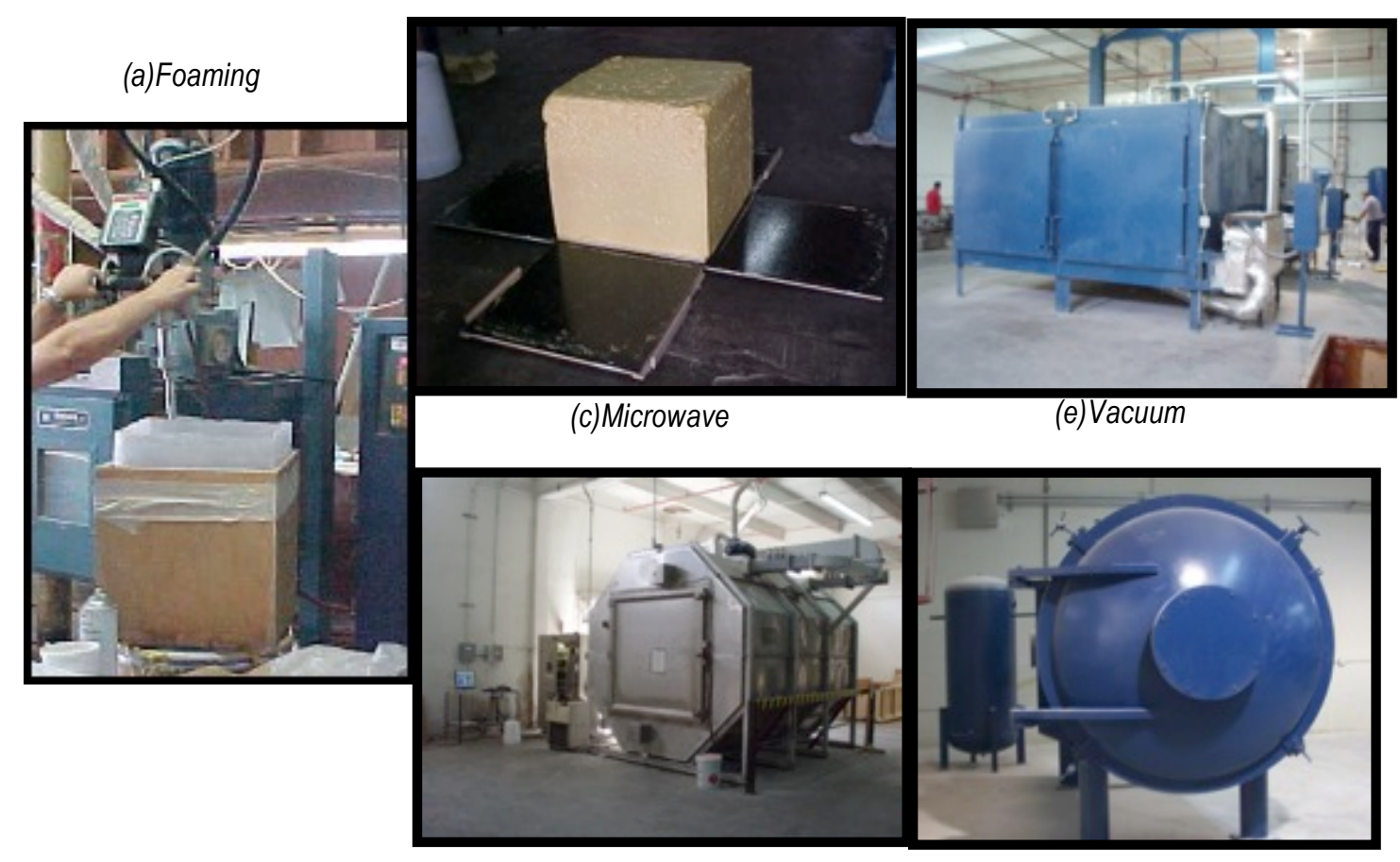

Figure 1: Process flow for polyimide foam currently being produced by PolyuMAC TechnoCore Inc.

\section{Material Characterization}

\section{A. General Approach}

It was of interest here to establish whether the acoustical performance of the processed polyimide foam could be predicted using conventional predictive tools. Here the foam was modeled as a homogeneous, isotropic poro-elastic medium, whose macroscopic properties are represented by the so-called Biot parameters ${ }^{5}$. Those parameters include the bulk density, flow resistivity, Young's modulus, porosity, tortuosity, viscous and thermal characteristic length, Poisson's ratio and structural loss factor. In the present work, the first three of these parameters were determined by 
direct measurement: details regarding the Young's modulus and flow resistivity measurements are given in the next two sections. The remaining six parameters were determined through an inverse characterization process, in which model predictions were compared with measurements of normal incidence absorption coefficient and transmission loss made in a standing wave tube: that process is described in Section II.D, below.

In this study, initial small samples of the $9.6 \mathrm{~kg} / \mathrm{m}^{3}(0.6 \mathrm{pcf})$ and the $5.4 \mathrm{~kg} / \mathrm{m}^{3}(0.34 \mathrm{pcf})$ density foams were compressed in the rise direction to a specified $\%$ of their original thickness (i.e., $80 \%, 60 \%, 50 \%, 40 \%, 20 \%, 10 \%$ ) and then tested for stiffness and flow resistance (Sections II.B. and II.C). These were then tested in the Purdue impedance tube to determine absorption and transmission loss. This data was processed using the inverse characterization of Section II.D to extract the Biot parameters. These parameter models were then used in an SEA model to choose that level of foam compression that produced the best transmission loss. These foam compression levels were then used to process the foam for large scale TL window testing.

\section{B. Stiffness Measurement}

An Instron 5848 MicroTester was used to obtain the Young's modulus of the foam. In order to determine the modulus, a measured level of compressive load is applied up to a $10 \%$ strain level using the following process. Samples are measured in inches in three directions to two decimal places. Using the Instron MicroTester these samples are tested at a displacement rate of $5 \mathrm{~mm} / \mathrm{min}$. to 10 percent compressive strain and the Young's modulus is extracted. The compression applied in this test is distinct from the material processing described in section II.A to improve the acoustic properties of the material.

Figure 2 shows the effect of compressing a $6.4 \mathrm{~kg} / \mathrm{m}^{3}$ ( $0.4 \mathrm{pcf}$ ) foam on the resultant modulus. Compression is defined as a $\%$ of the original thickness. Compressing the foam once in the rise direction from 90 to 5 percent of its original thickness then allowing it to recover (nominal $>90$ percent recovery of height within 24 hours) results in a measured and systematic modulus reduction. Here the modulus was reduced from the original $180 \mathrm{kPa}$ to $66 \mathrm{kPa}$. The error bars indicate the standard deviation of the modulus across the samples tested. Figure 3 shows scanning electronic micrographs (SEM) of how the compression opens the cell membranes and buckles the cell struts.

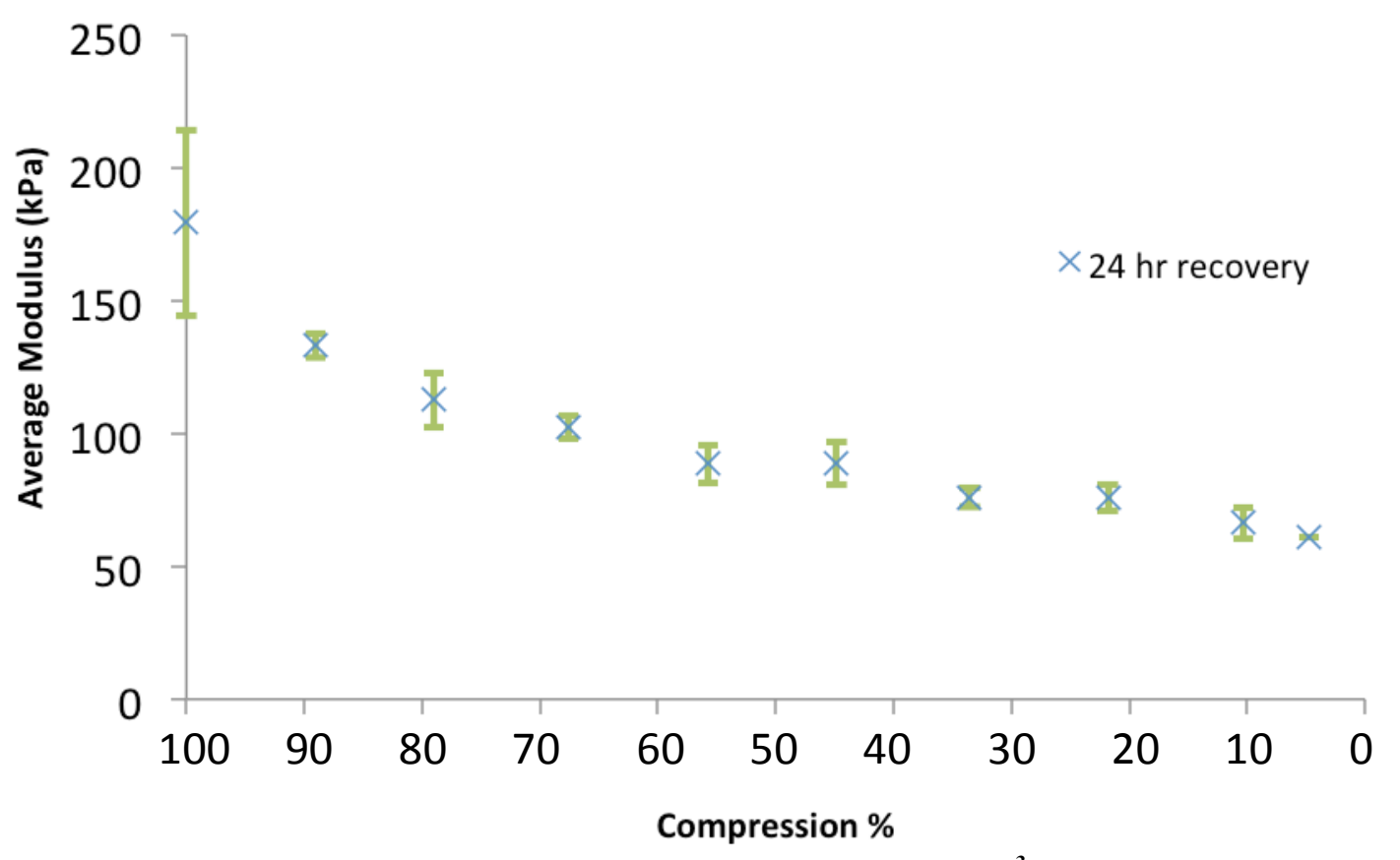

Figure 2: Youngs Modulus vs. compression level for $6.4 \mathrm{~kg} / \mathrm{m}^{3}$ (0.4 pcf) foam after a relaxation time of 24 hours. 


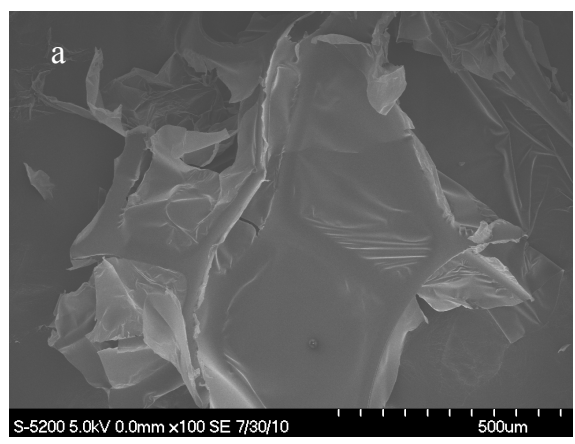

Figure 3: SEM Photographs of $6.4 \mathrm{~kg} / \mathrm{m}^{3}(0.4$ pcf) polyimide foam samples: a. uncompressed; $b$. compressed/recovered $60 \%$

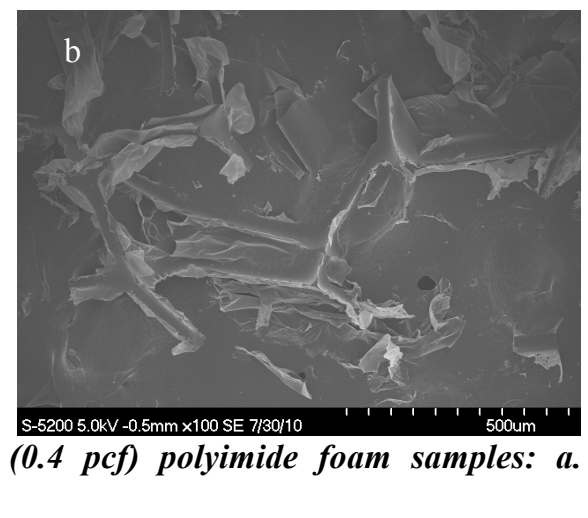

\section{Flow Resistivity Measurement}

Flow resistivity data was acquired using a raylometer operated by the Structural Acoustics Branch at NASA LaRC (Fig. 4). The raylometer determines flow resistance by measuring the difference in static pressure across a material sample for a given incident air velocity. The ratio of the static pressure difference to the incident velocity (in MKS units on a per meter basis) is the flow resistivity. A series of electronic mass flow controllers are used to meter out the precise amount of air required for a desired incident velocity. High-accuracy pressure transducers record the differential pressure from a series of static pressure taps located upstream and downstream of the sample. Figure 5 shows a representative sample of foam and the holder used to constrain the sample in the raylometer. Note that the sample is retained in the holder by highporosity, phenolic honeycomb with negligible flow resistance. For this investigation, ten, $5.08 \mathrm{~cm}$ ( 2 in.) cubic samples of the foam material were tested at incident flow velocities between $0.2 \mathrm{~cm} / \mathrm{sec}$ and $2 \mathrm{~cm} / \mathrm{sec}$. These incident velocities correspond to particle velocities that would bracket the range experienced in an aircraft sidewall installation. The ten samples were cut from $5.08 \mathrm{~cm}$ thick, $10 \mathrm{~cm}$ dia. impedance tube samples tested previously at Purdue.

Results from the resistivity measurements are shown in Fig. 6. Nominal average flow resistivity (extrapolated to $0 \mathrm{~cm} / \mathrm{sec}$ ) for this $6.4 \mathrm{~kg} / \mathrm{m}^{3}$ (0.4 pcf) foam ranged from $60000 \mathrm{MKS}$ Rayls $/ \mathrm{m}$ for the

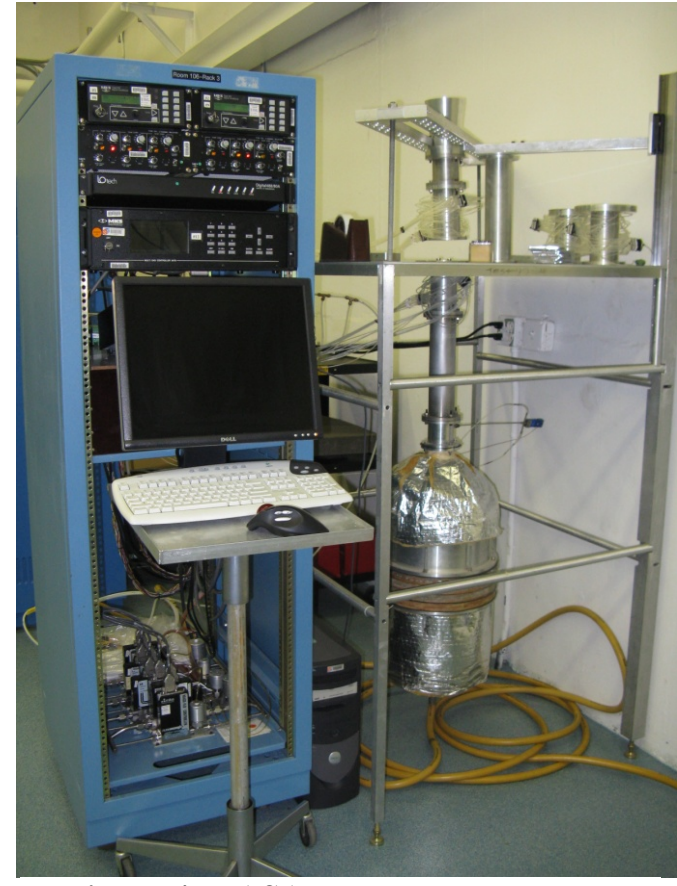

Figure 4: NASA Langley Raylometer

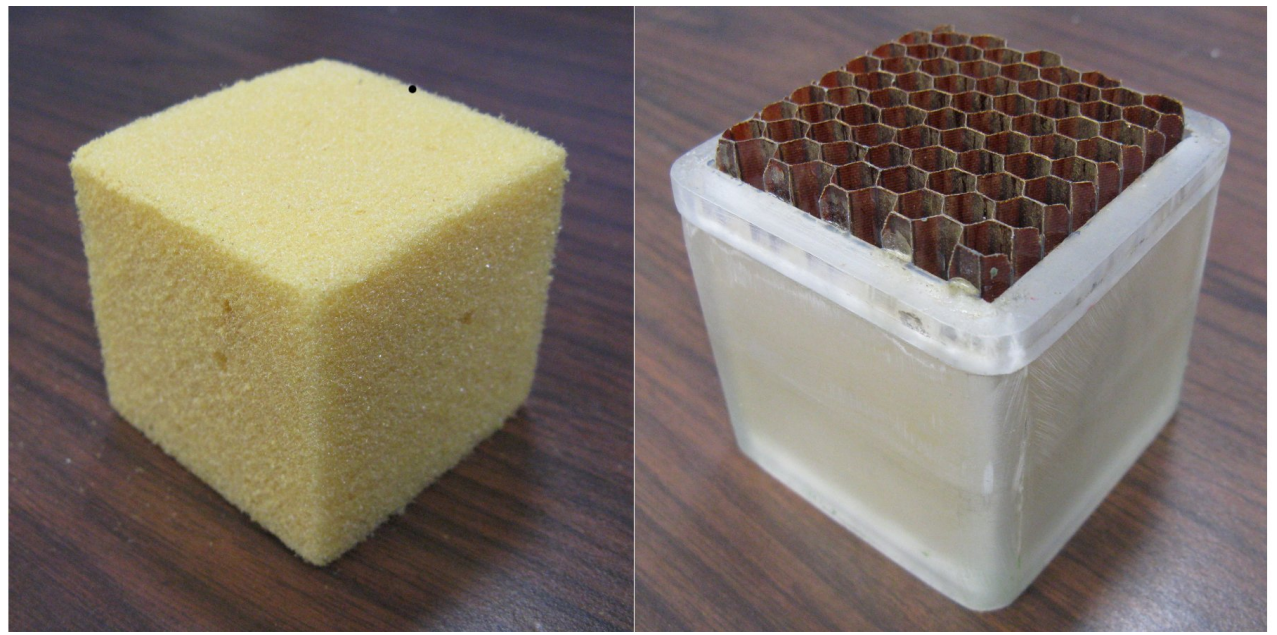

Figure 5: Representative polyimide foam sample and sample holder with honeycomb retainer. 


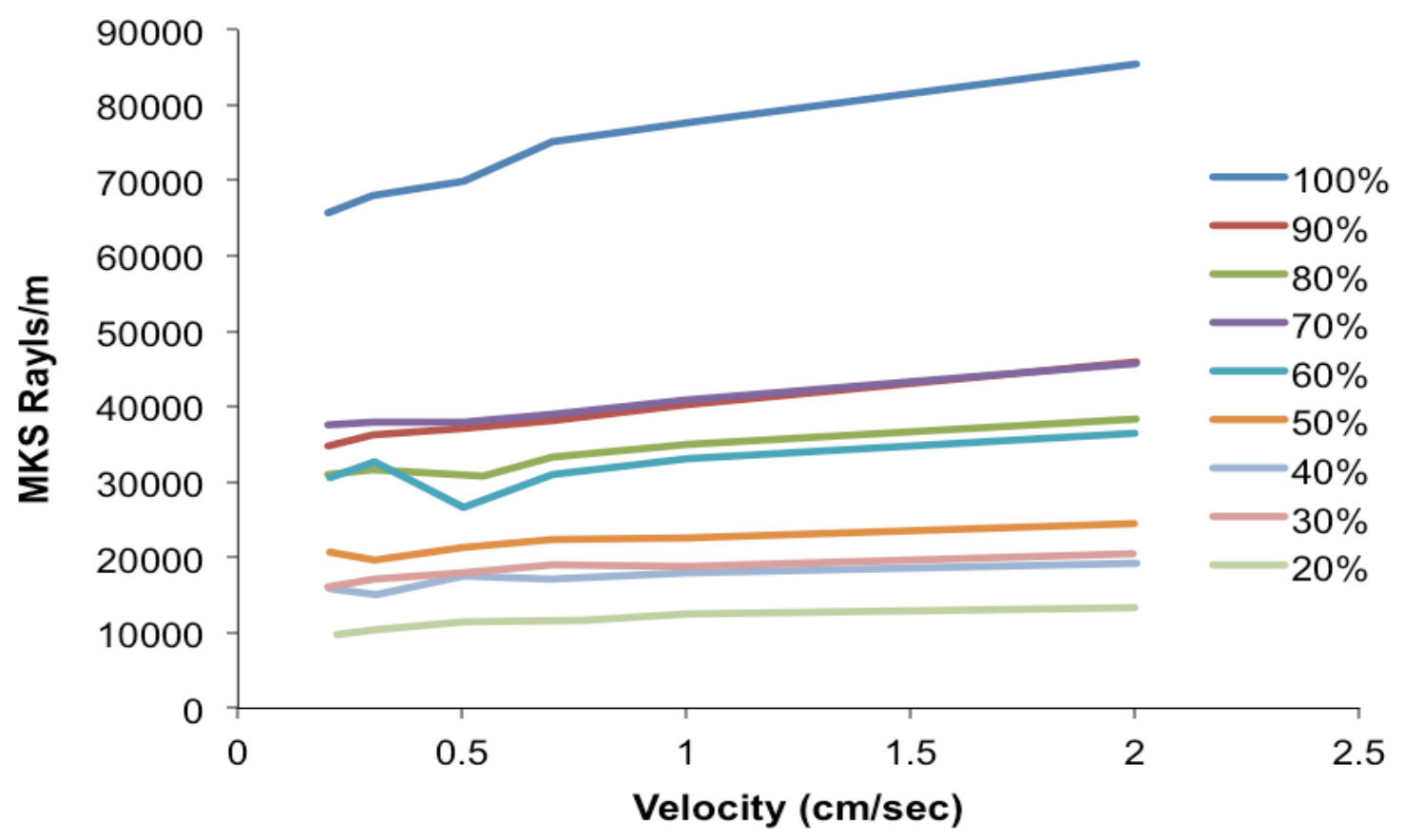

Figure 6: Flow Resistivity (MKS Rayls/m) vs. flow velocity for $6.4 \mathrm{~kg} / \mathrm{m}^{3}$ (0.4 pcf) foam varying level of compression (\% of original thickness) after a relaxation time of two weeks

"as supplied" material to 10000 MKS Rayls/m for the material compressed to $20 \%$ of its original thickness. While the flow resistivity is not completely monotonic in its relationship to compression level, variations were attributed to sample-to-sample variations. While not shown here, the compression was found to significantly reduce the standard deviation of the flow resistivity between the test samples resulting in much more uniform samples.

From these initial studies, it was found that a single compression cycle in the rise direction would consistently reduce both the modulus and the flow resistance. The more the material was compressed, the lower the modulus and the flow resistance. Further, the compression reduced the standard deviation of both the modulus and flow resistivity across the samples tested. This material seems especially amenable to simple compression as a process to improve the acoustic properties. This is assumed to be due to less robust frame and membrane structures that are easily broken. Other studies ${ }^{6}$ of Polyimide foams derived from alternative formulations required more complex approaches to breaking down this structure to make them suitable for acoustic applications. Finally, compression of the lower density material too much was found to result in a flow resistivity that was too low. Therefore care should be taken in optimizing the acoustic properties.

\section{Inverse Characterization}

The Biot properties other than bulk density, flow resistivity, Young's modulus and porosity were estimated by using an inverse characterization procedure. Note that the porosity was fixed at 0.99 , which is typical for sound absorbing materials. In this approach, samples of foam were tested in both two and four-microphone standing wave tubes $^{7,8}$ to measure their normal incidence absorption coefficient (with the sample placed flush against a hard backing) and normal incidence transmission loss. Ten, $5 \mathrm{~cm}$ deep samples of both $10 \mathrm{~cm}$ and $2.9 \mathrm{~cm}$ diameters were tested, to produce average absorption coefficients and transmission losses. The measurements were then provided as input to a version of the software COMET/Trim that matches transmission loss and absorption coefficients by adjusting model parameters. In this case, density, flow resistivity and Young's modulus were fixed at their measured values, and the porosity was fixed at 0.99 as noted. The remaining five parameters were estimated by using an optimization procedure built into COMET/Trim. The version of COMET/Trim used in this work was based on the finite element software COMET/Safe that implements the Biot poro-elastic theory. It is necessary to use a finite element-based procedure to account for the effects of the sample constraint due to friction around its circumferential edge. ${ }^{9,10,11}$ The latter constraint can introduce a low frequency, shearing resonance of the sample, which is particularly noticeable in transmission loss measurements. A finite-element-based inverse procedure can reproduce the latter feature, and enhances the ability of the inverse characterization to identify the stiffness 
properties of the material. This procedure is described in detail in Ref. 11, along with guidelines to establish how many parameters can be successfully identified by inverse methods. The Biot parameters for the polyimide foam considered here, determined from the combination of direct measurements and the inverse characterization described above, are listed in Table 1.

Table 1: Biot parameters for polyimide foams tested at the Gulfstream Acoustic Test Facility .

\begin{tabular}{|c|c|c|c|}
\hline & $\begin{array}{l}9.6 \mathrm{~kg} / \mathrm{m}^{3}(0.6 \mathrm{pcf}) \\
\text { compressed to } 10 \% \text { of } \\
\text { original thickness }\end{array}$ & $\begin{array}{l}5.4 \mathrm{~kg} / \mathrm{m}^{3}(.34 \mathrm{pcf}) \\
\text { compressed to } 50 \% \text { of } \\
\text { original thickness }\end{array}$ & $\begin{array}{l}5.4 \mathrm{~kg} / \mathrm{m}^{3}(.34 \mathrm{pcf}) \\
\text { compressed to } 20 \% \text { of } \\
\text { original thickness }\end{array}$ \\
\hline Density $\left(\mathrm{kg} / \mathrm{m}^{3}\right)$ & 9.6 & 5.4 & 5.4 \\
\hline Flow resistivity (MKS Rayls/m) & 29000 & 40000 & 10000 \\
\hline Porosity & 0.99 & 0.99 & 0.99 \\
\hline Tortuosity & 3.11 & 2.11 & 1.02 \\
\hline $\begin{array}{l}\text { Viscous characteristic length } \\
\left(10^{-6} \mathrm{~m}\right)\end{array}$ & 66.9 & 44.0 & 38.2 \\
\hline $\begin{array}{l}\text { Thermal characteristic length } \\
\left(10^{-6} \mathrm{~m}\right)\end{array}$ & 268 & 51.1 & 59.1 \\
\hline Young's modulus (kPa) & 135 & 76 & 27 \\
\hline Loss factor & 0.42 & 0.21 & 0.0034 \\
\hline Poisson's ratio & 0.21 & 0.012 & 0.46 \\
\hline
\end{tabular}

\section{Characterization of Transmission Loss}

\section{A. Measurement of Transmission Loss}

The $1.2 \mathrm{~m} \times 1.2 \mathrm{~m}$ foam panels utilized for TL testing were provided by PolyuMAC as precut specimens that were compressed at NASA LaRC to a specified percent of their thickness, allowed to recover then shipped to Gulfstream Aerospace Corporation (GAC) for full-scale transmission loss testing. The same material samples were subsequently shipped to Purdue to obtain standing wave tube data and then shipped back to NASA where samples were cut to measure the flow resistivity and the modulus of the previously compressed foam. This procedure allowed all of the parameters of the actual material tested to be characterized.

The sound transmission loss of a double-wall structure, in which the foam acts as the absorptive layer, was measured in the GAC Acoustic Test Facility (ATF) using the ASTM E2249 standard. ${ }^{12}$ The test setup consisted of the test structure mounted in a $1.2 \mathrm{~m} \times 1.2 \mathrm{~m} \times 0.14 \mathrm{~m}$ transmission loss window between a $252 \mathrm{~m}^{3}$ reverberation chamber and a $215 \mathrm{~m}^{3}$ hemi-anechoic chamber. The test structure, shown in Fig. 7 comprised two, $1 \mathrm{~mm}$ aluminum panels, one layer of $7.6 \mathrm{~cm}$ thick polyimide foam and two $2.54 \mathrm{~cm}$ air gaps between the foam and each aluminum panel. The foam was supported on both sides at the perimeter by $2.54 \mathrm{~cm} \times 2.54 \mathrm{~cm}$ wood spacers, which also acted as the standoff for the aluminum panels. An acoustic duct sealant was used at the edges to provide protection against acoustic flanking.

The noise level in the source reverberation room was measured with a rotating boom microphone, and the transmitted energy was measured by a scanning sound-intensity probe. The transmission loss was calculated according to Ref. 12 . The three different polyimide foam samples specified in Table 1 as well as a $6.7 \mathrm{~kg} / \mathrm{m}^{3}(0.42$ pcf) glass fiber sample were tested in the Gulfstream ATF.

\section{B. Prediction of Transmission Loss}

The transmission loss of the double-wall structure shown in Fig. 7 was predicted by Boeing Commercial Airplane Company with the Statistical Energy Analysis (SEA) software VA One. ${ }^{13}$ The TL prediction method is based on simulating the ASTM E- $90^{14}$ sound transmission loss standard using two reverberation rooms: see Fig. 8. The modeled configuration was a double wall system with $1 \mathrm{~mm}$ thick aluminum face sheets, $2.54 \mathrm{~cm}$ air gaps and a centered $7.6 \mathrm{~cm}$ thick polyimide foam layer, using the foam properties as defined in Section II and Table 1.

6

American Institute of Aeronautics and Astronautics 


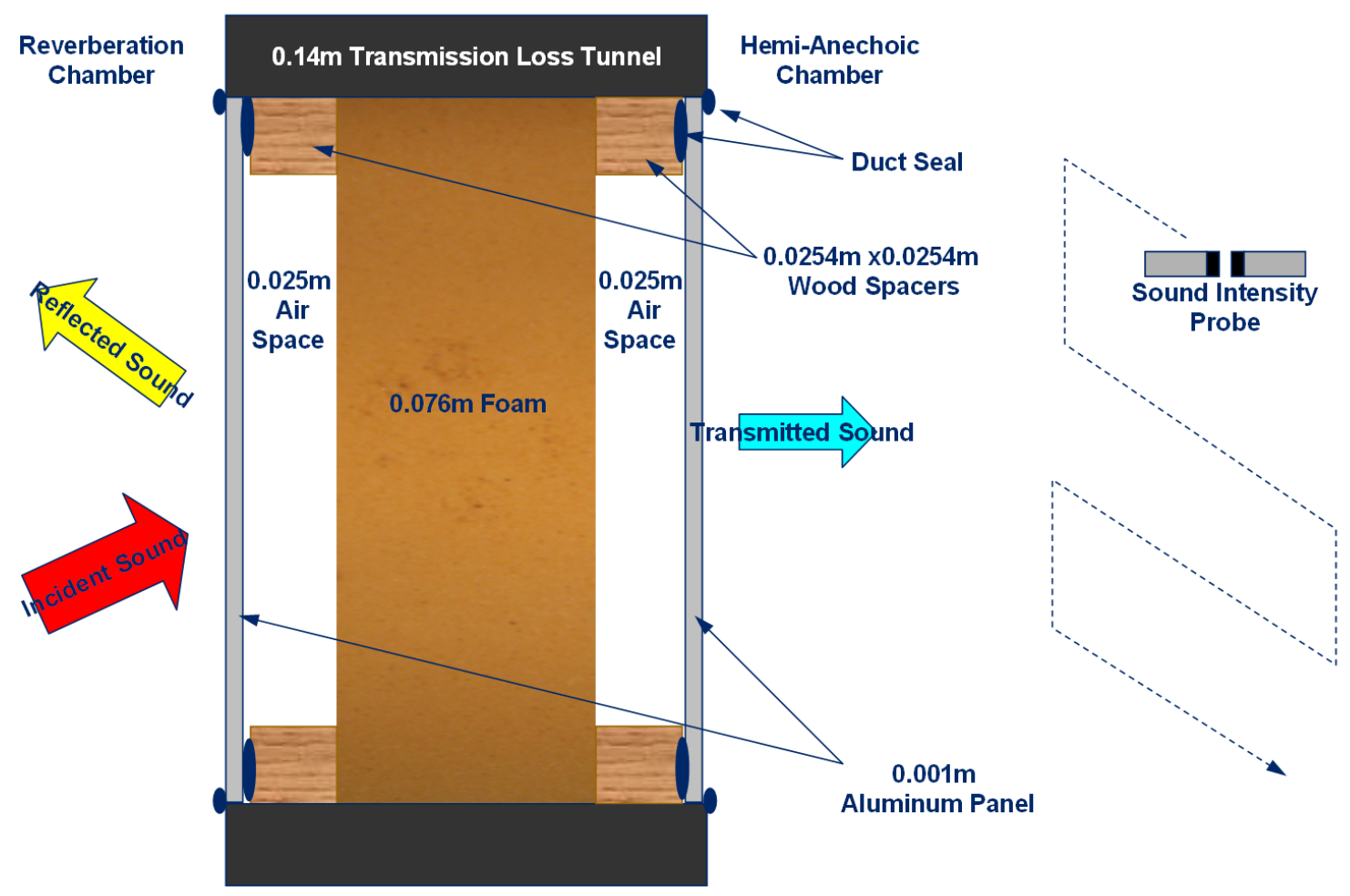

Figure 7: Transmission loss test setup of the double-wall structure

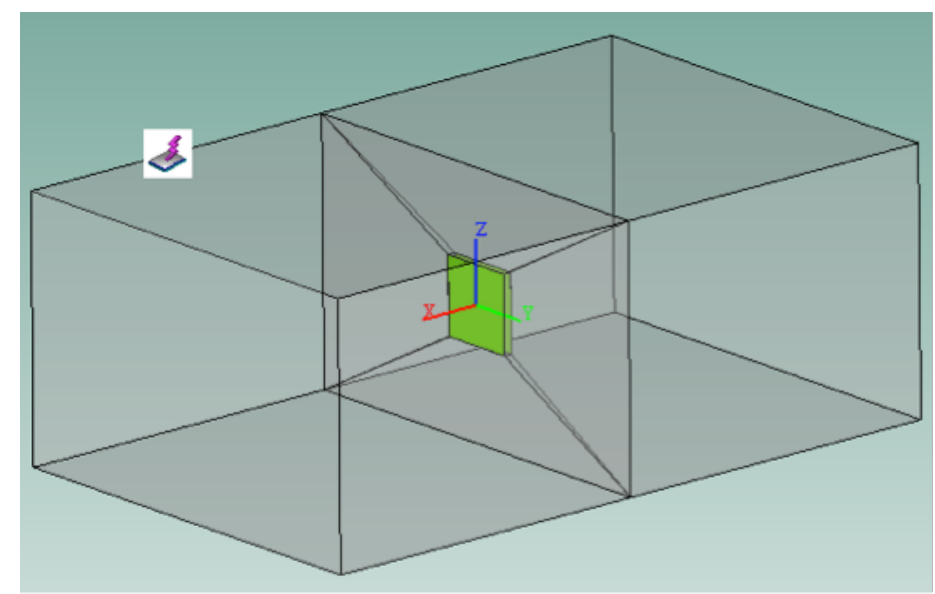

Figure 8: Double wall TL model in VA One.

\section{Results - Comparison of Measured and Predicted Transmission Loss}

The VA One prediction for the $9.6 \mathrm{~kg} / \mathrm{m}^{3}$ foam compressed to $10 \%$ of its original thickness is compared to the experimental data in Fig. 9. The prediction correlates well with the experimental data below $630 \mathrm{~Hz}$ and above 4000 Hz. However, the transmission loss is under-predicted in the mid-frequency range where a peak in the measured TL occurs in the $1000 \mathrm{~Hz}$ one-third octave band for which the cause has not been identified.

For the $5.4 \mathrm{~kg} / \mathrm{m}^{3}$ polyimide foam, two levels of compression ( $50 \%$ and $20 \%$ of initial thickness) were examined to understand the effect of compression on the transmission loss. The original foam panels were compressed to $50 \%$, tested in the Gulfstream ATF and then these same panels were compressed to $20 \%$ of original thickness and tested again. These same panels were then sent to Purdue and NASA for characterization. The measured values for the 
flow resistance and stiffness are itemized in Table 1. The flow resistance was reduced by a factor of 4 and

\section{Transmission Loss of the Double-Wall Structure}

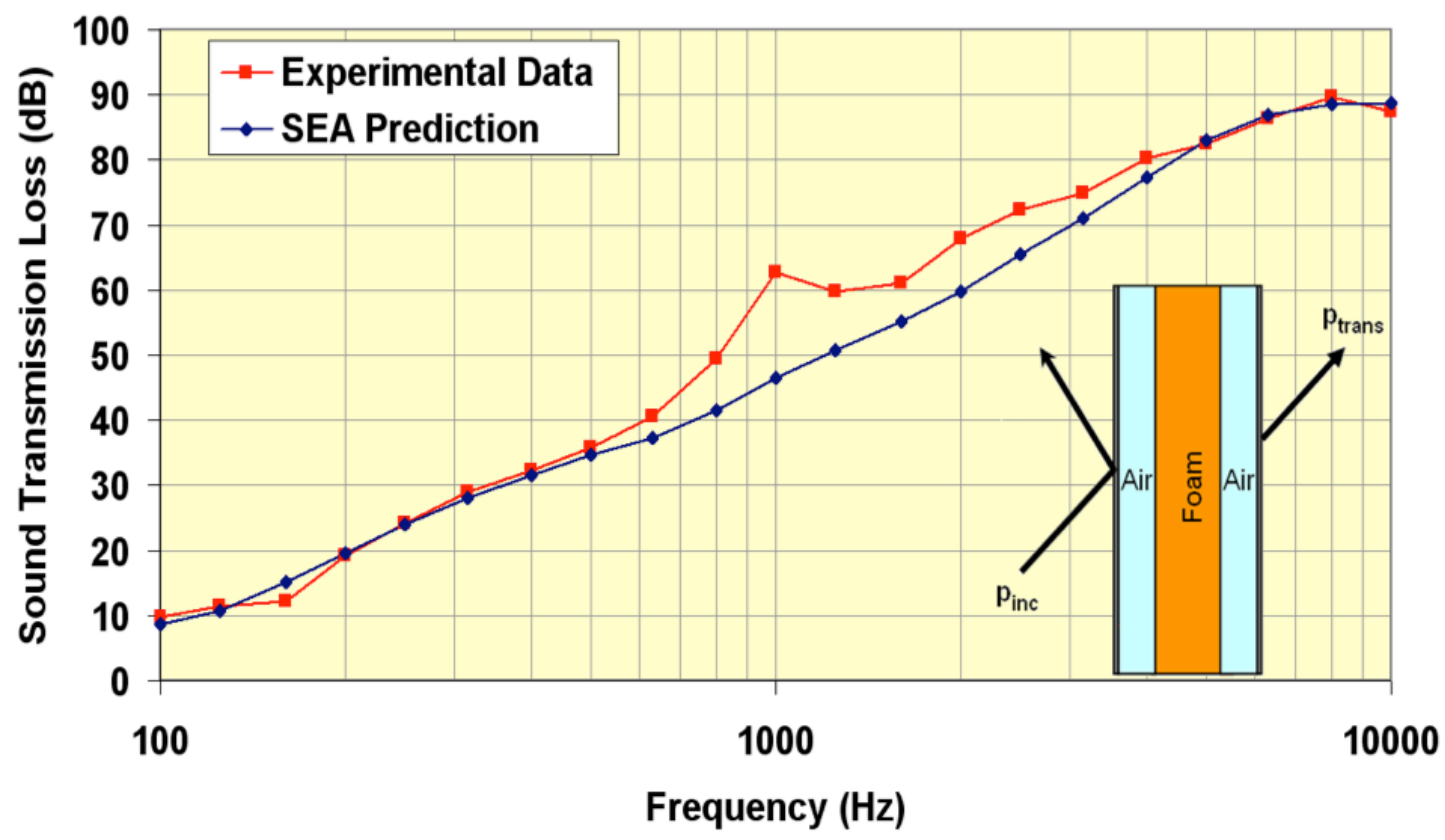

Figure 9: Comparison of the SEA predictions to the experimental data for $9.6 \mathrm{~kg} / \mathrm{m}^{3}(0.6 \mathrm{pcf})$ compressed to $10 \%$ of its original thickness.

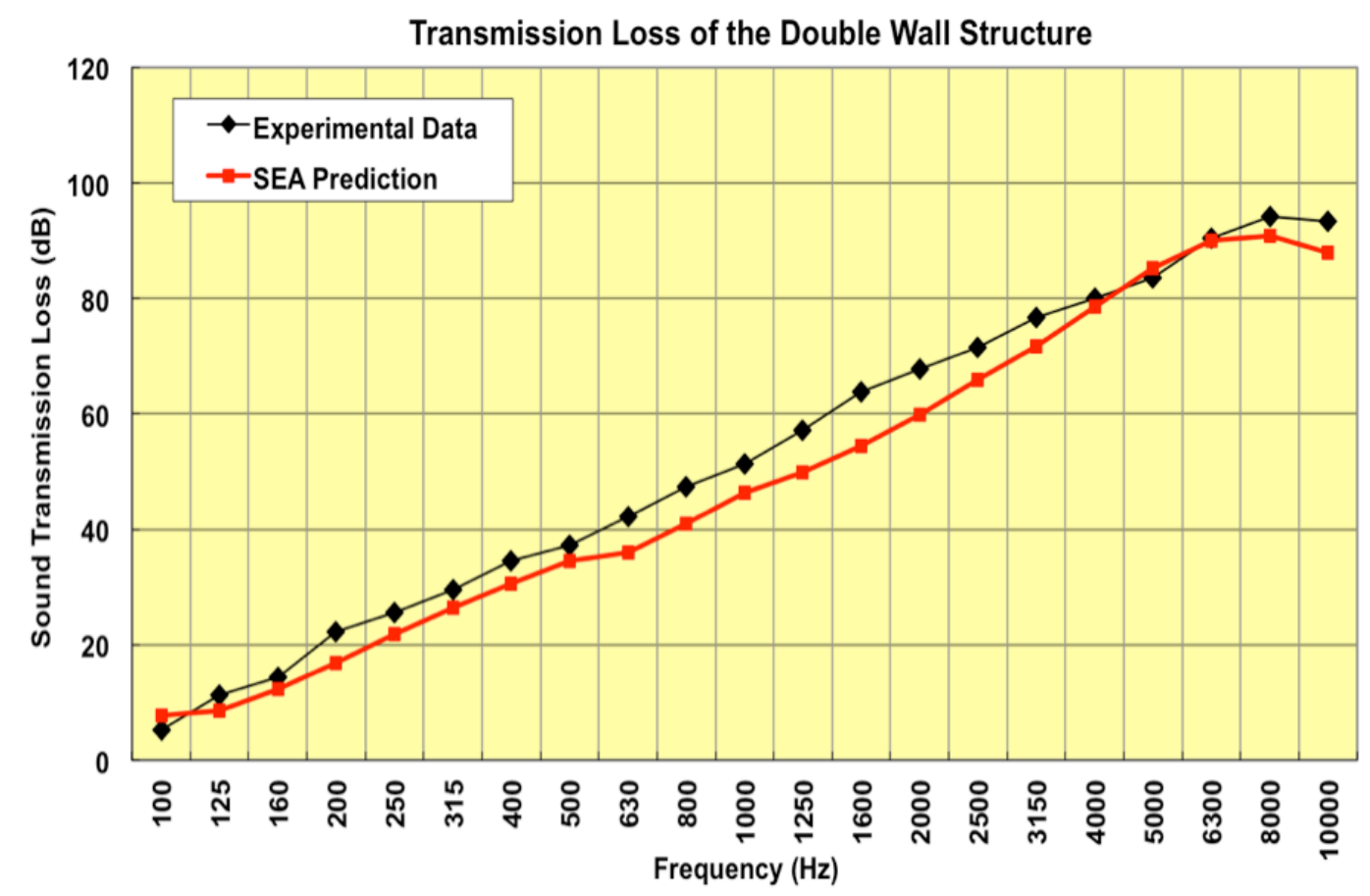

Figure 10: Comparison of the SEA predictions to the experimental data for $5.4 \mathrm{~kg} / \mathrm{m}^{3}$ (0.34 pcf) compressed to $50 \%$ o its original thickness. 
the stiffness by a factor of 3 . The $50 \%$ compression was projected to be the optimum level for TL performance. It should be noted that for this case only, the parameter extraction was based on tests performed on foam samples obtained from the same batch as that tested at GAC, but not the exact foam. As noted above, the $50 \%$ material was further compressed $20 \%$ for a second round of testing and thus the TL tested $50 \%$ foam could not be fully characterized at this compression level post the initial Gulfstream testing.

The comparison between the VA One prediction for the $5.4 \mathrm{~kg} / \mathrm{m}^{3}$ compressed to $50 \%$ of its original thickness is compared to the experimental data in Fig. 10. The prediction correlates well with the experimental data across the frequency range with the trend being consistent. The transmission loss is under-predicted by 9 to $10 \mathrm{~dB}$ in the midfrequency range centered around the 1600 one-third octave band.

The comparison between the VA One prediction and the measurements for the $5.4 \mathrm{~kg} / \mathrm{m}^{3}$ foam compressed to $20 \%$ of its original thickness is shown in Fig. 11 . The prediction correlates similarly with the experimental data below $500 \mathrm{~Hz}$ but then under-predicts the measurement by $9 \mathrm{~dB}$ at $630 \mathrm{~Hz}$, reducing to $6 \mathrm{~dB}$ out to $2000 \mathrm{~Hz}$. Above $4 \mathrm{kHz}$, SEA over-predicts the measurement. However, in general the correlation is reasonable across the frequency range.

Finally Fig. 12 shows the test data comparison between the two $5.4 \mathrm{~kg} / \mathrm{m}^{3}(0.34 \mathrm{pcf})$ foams and a $6.7 \mathrm{~kg} / \mathrm{m}^{3}(0.42$ pcf) Johns Manville aircraft grade fiberglass for sound transmission loss. The glass fiber out-performs the polyimide foams by 3 to $4 \mathrm{~dB}$ at frequencies greater than $630 \mathrm{~Hz}$. The foam compressed to $50 \%$ of its original thickness is comparable to the $20 \%$ foam out to $1250 \mathrm{~Hz}$ but then out-performs the $20 \%$ foam at higher frequencies. As predicted, overall the $50 \%$ foam out-performed the $20 \%$ foam, but both have poorer acoustic performance than the standard glass fiber. The glass fiber is somewhat heavier, but mass law alone does not account for the differences.

\section{Transmission Loss of the Double Wall Structure}

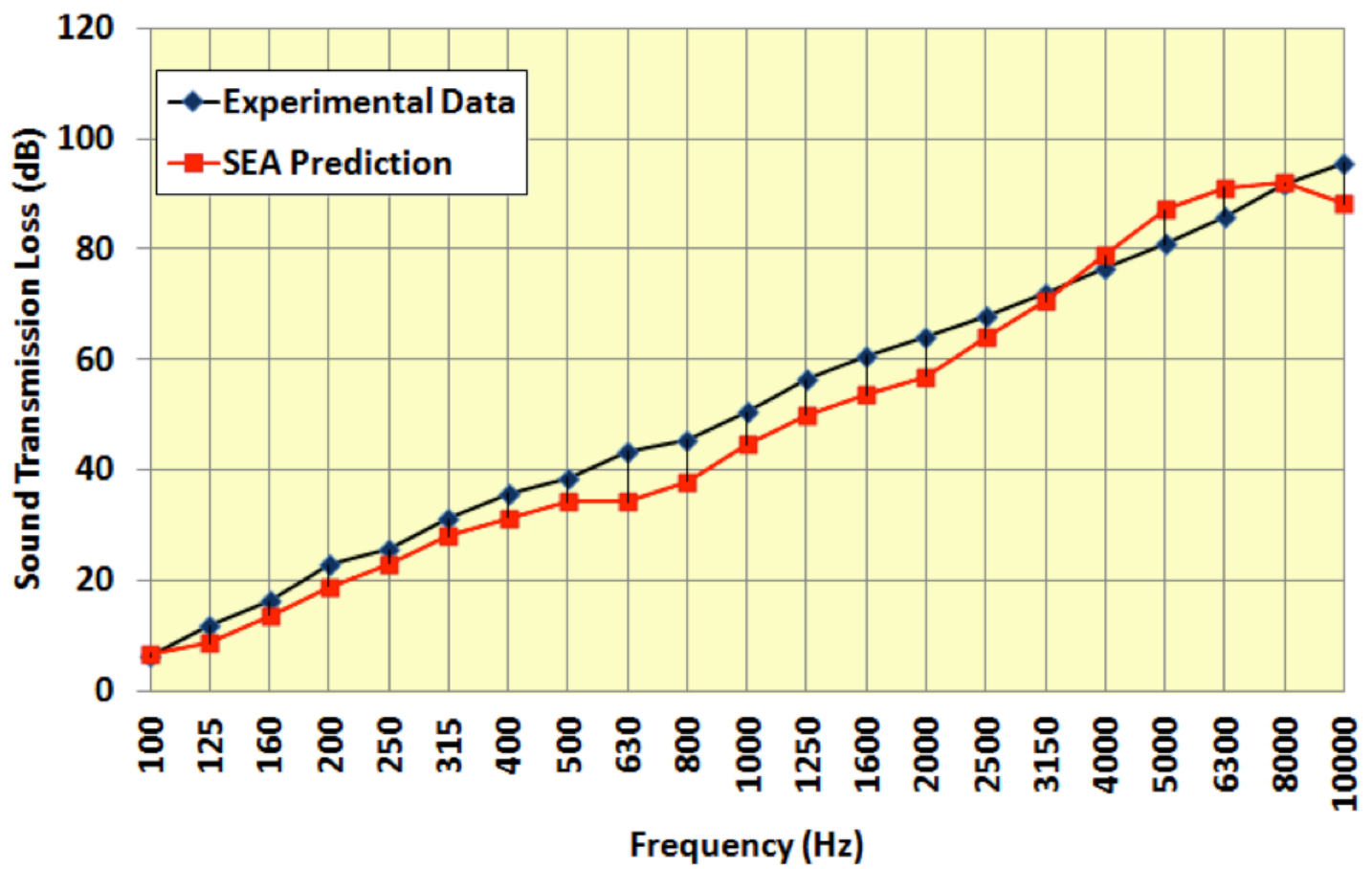

Figure 11: . Comparison of the SEA predictions to the experimental data for $5.4 \mathrm{~kg} / \mathrm{m}^{3}$ ( $0.34 \mathrm{pcf}$ ) compressed to $20 \%$ of its original thickness. 


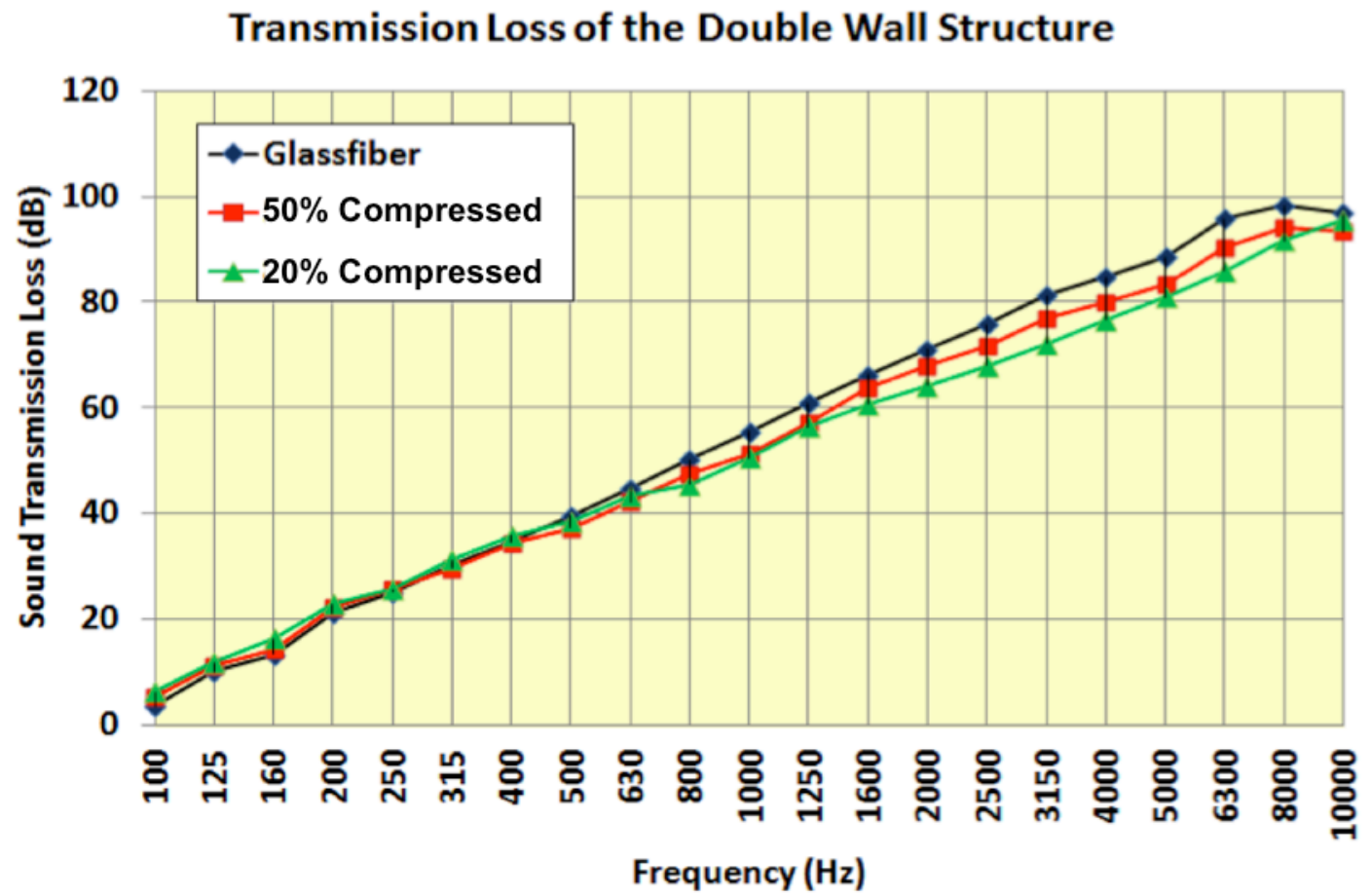

Figure 12: Comparison of the measured transmission loss of the two configurtions of the $5.4 \mathrm{~kg} / \mathrm{m}^{3}(0.34 \mathrm{pcf})$ polyimide foam and a $6.7 \mathrm{~kg} / \mathrm{m}^{3}(0.42 \mathrm{pcf})$ glass fiber material.

\section{Concluding Remarks}

The work described in this paper was focused on the use of a new polyimide foam in a double wall sound transmission loss application. Polyimide foams are functionally attractive, compared to polyurethane foams, for example, owing to their fire resistance. They may be treated to be hydrophobic which may negate the need for further packaging. Further, these foams may be made free standing and custom fit to aircraft frame structures, filling all voids. The $5.4 \mathrm{~kg} / \mathrm{m}^{3}$ polyimide foam is $15 \%$ lighter than a comparable glass fiber material currently used in aircraft today. The original foam considered here was found to have a flow resistivity that was too high for conventional acoustic applications. However, it was easily processed by partial compression to lower the flow resistivity and modulus into an acceptable range. Procedures for measuring the flow resistivity and Young's modulus of the material have been described, as was an inverse characterization procedure for estimating the remaining Biot parameters based on standing wave tube measurements of transmission loss and absorption coefficient. The inverse characterization was performed using a finite element model implementation of the Biot poro-elastic material theory. Those parameters were then used to predict the sound transmission loss of a double panel system lined with polyimide foam, and the predictions were compared with full-scale transmission loss measurements. The agreement between the prediction and measurement was reasonable; however, it was found that the SEA model consistently under-predicted the transmission loss in the mid-frequency range. Nonetheless, it was concluded that the performance of polyimide foam could be predicted using conventional poro-elastic material models and that polyimide foam may offer an attractive alternative to other acoustic materials in certain situations.

\section{Acknowledgements}

The authors are grateful to Kevin Lai and Evan Davis of the Boeing Commercial Airplane Company who provided the VA-One SEA predictions and Tongan Wang and John Maxon of Gulfstream Aerospace Corporation who provided the transmission loss measurements. The authors also wish to thank both of these groups for their thorough discussion of results and comparisons to measurements. Thanks are also extended to the NASA Fixed Wing and Rotary Wing projects of the Fundamental Aero Program for providing support. 


\section{References}

${ }^{1}$ Tsoi, W., "Acoustical Modeling of Polyimide Foam", M.S.M.E. Thesis, Ray W. Herrick Laboratories, School of Mechanical Engineering, Purdue University, West Lafayette, IN, 1992.

${ }^{2}$ Kang, Y.J., Tsoi, W. and Bolton, J.S., "The Effect of Mounting on the Acoustical Properties of Finite-Depth Polyimide Foam Layers," Proceedings of NOISE-CON 93, Williamsburg, VA 1993, pp. 285-290.

${ }^{3}$ Vazquez, J.M., Cano, R.J., Jensen, B.J. and Weiser, E.S., "Polyimide Foams," U.S. Patent No. 6,956,066 (2005).

${ }^{4}$ Vazquez, J.M., Cano, R.J., Jensen, B.J. and Weiser, E.S., "Polyimide Foams," U.S. Patent No. 7,541,388 (2009).

${ }^{5}$ Allard, J. F. and Atalla, N., "Propagation of Sound in Porous Media: Modelling Sound Absorbing Materials (second edition)", Wiley, 2009.

${ }^{6}$ Doutres, O., Atalla, N., Wulliman, R., Ferguson, S. and Bailey, S., "Optimization of the acoustic performance of Polyimide foams," Proceedings of NOISE-CON 2011, Portland, OR, 2011.

${ }^{7}$ Song, B.H. and Bolton, J.S., "A Transfer Matrix Approach for Estimating the Characteristic Impedance and Wave Number of Limp and Rigid Porous Materials," Journal of the Acoustical Society of America, Vol. 107, 2000, pp. 1131-1152.

${ }^{8}$ Olivieri, O., Bolton, J.S., and Yoo, T., "Measurement of Transmission Loss of Materials Using a Standing Wave Tube," Proceedings of INTER-NOISE 2006, paper 374, 8 pages, Honolulu, HI, 2006.

${ }^{9}$ Song, B.H., Bolton, J.S. and Kang, Y.J., "Effect of Circumferential Edge Constraint on the Acoustical Properties of Glass Fiber Materials," Journal of the Acoustical Society of America, Vol. 110, 2001, pp. 2902-2916.

${ }^{10}$ Hong, K. and Bolton, J.S., "The Effect of Sample Edge Conditions on Standing Wave Tube Measurements of Absorption and Transmission Loss," Proceedings of the $15^{\text {th }}$ International Congress on Sound and Vibration, Daejon, Korea, 8 pages, 2008.

${ }^{11}$ Hong, K., "Acoustical Estimation of Macroscopic Properties of Poroelastic Materials", Ph.D. Thesis, Ray W. Herrick Laboratories, School of Mechanical Engineering, Purdue University, West Lafayette, IN, 2009.

${ }^{12}$ ASTM Standard E2249-02, "Standard Test Method for Laboratory Measurement of Airborne Transmission Loss of Building Partitions and Elements Using Sound Intensity", ASTM International, 2002.

${ }^{13}$ VA One ver-2008.5, http://www.esi-group.com/products/vibro-acoustics/va-one/Overview/

${ }^{14}$ ASTM Standard E90-04, "Standard Test Method for Laboratory Measurement of Airborne Sound Transmission Loss of Building Partitions and Elements", ASTM International, 2004. 